\title{
The Photosynthetic Characteristics of Different Purple Peppers
}

\author{
Yu Huang ${ }^{1}$, Xiaohui Wang ${ }^{2}$, Wu Miao ${ }^{3}$, Huan Suo ${ }^{1}$, Canfang Fu ${ }^{1}$, Meng Chen ${ }^{1}$, Xuanhua Zhao ${ }^{1}$ \\ and Lijun $\mathrm{Ou}^{1, *(1)}$
}

1 Engineering Research Center of Education Ministry for Germplasm Innovation and Breeding New Varieties of Horticultural Crops, Hunan Agricultural University, Changsha 410128, China; huangyu128@139.com (Y.H.); shuan2722@hunau.edu.cn (H.S.); fu2452859101@163.com (C.F.); ep970513@163.com (M.C.); fs11832744604@163.com (X.Z.)

2 College of Life Science, Hunan Normal University, Changsha 410081, China; xnhuangyu@163.com

3 Hunan Xiangyan Seed Industry Co, Ltd., Changsha 410100, China; maolz77@163.com

* Correspondence: ou9572@hunau.edu.cn; Tel.: +86-153-8809-7309

Citation: Huang, Y.; Wang, X.; Miao, W.; Suo, H.; Fu, C.; Chen, M.; Zhao, X.; Ou, L. The Photosynthetic Characteristics of Different Purple Peppers. Horticulturae 2021, 7, 304. https://doi.org/10.3390/

horticulturae7090304

Academic Editor: Peter A. Roussos

Received: 22 July 2021

Accepted: 8 September 2021

Published: 10 September 2021

Publisher's Note: MDPI stays neutral with regard to jurisdictional claims in published maps and institutional affiliations.

Copyright: (c) 2021 by the authors. Licensee MDPI, Basel, Switzerland. This article is an open access article distributed under the terms and conditions of the Creative Commons Attribution (CC BY) license (https:// creativecommons.org/licenses/by/ $4.0 /)$.
Abstract: The yield of pepper with purple leaves (PF) is low, while the pepper with green leaves (GM) is not resistant to strong light and high temperature. In this study, we analyzed the photosynthesis characteristics and genetic stability of their hybrid progenies using PF(CS3) and GM(SJ11-3) as controls. Based on the decreased purple color and increased green color, the hybrid pepper was divided into five groups: Z1, Z2, Z3, Z4 and Z5. Results showed that as the purple color increased, the anthocyanin content in leaves increased. Simultaneously, we found that PF exhibited higher resistance to strong light and high temperature. Thus, the purple hybrid progenies with higher photosynthetic rate were recommended, as they showed higher yield and better resistance to strong light and high temperature.

Keywords: pepper; anthocyanin; strong light; high temperature; photosynthetic rate

\section{Introduction}

Pepper (Capsicum annuum L.) belongs to the genus Capsicum and family Solanaceae. It originates from the tropical regions of Mexico and Central-South America. There are many types of germplasm resources for pepper, and the purple pepper is one of the rare types. Unlike the common green peppers, the cotyledons, stems, leaves, flowers, and fruits of purple peppers are purple and have higher content of anthocyanins. Purple peppers exhibit good resistance to environmental stresses, such as high temperature and drought. Moreover, the purple pepper also shows some resistant characteristics to pests [1-4].

The purple trait of plants is a macroscopic trait that can be observed at the seedling stage and stably inherited throughout the growth period. Thus, it is often used for the detection of hybrid purity and the labeling of related traits. The purple trait of peppers has not yet been widely used. It is mainly applied in resistance breeding, such as the "Ziyan No.1" [5] and "Zijin No.1" [6], which are resistant to low temperature and low light. Additionally, the heredity of pepper purple trait is complicated. It is a two-pair additive-dominant-epistatic major gene + additive-dominant-epistatic polygene genetic model. Since there are many key genes involved in anthocyanin metabolism [7], the hybrid progenies often show different degrees of purple trait, which increases the difficulty of breeding. In this study, we used the multi-generation stable genetic germplasms from the isolated hybrid progenies of pepper with purple leaves and pepper with green leaves as the research materials. These plants had different degrees of purple traits. By analyzing their photosynthetic features, we aimed to elucidate the response characteristics of purple leaves with different anthocyanin contents to strong light and high temperature, in order to provide a practical guide for applying the purple trait in pepper breeding. 


\section{Materials and Methods}

\subsection{Materials}

The $\mathrm{F}_{2}$ generation of purple leaf pepper CS3 (PF) and green leaf pepper SJ11-3 (GM) was used as the experimental material, with PF and GM as controls. On the day 25 after planting, 5 representative purple types were selected based on the color of the fifth leaf from the growth point. These purple types were named as Z-1, Z-2, Z-3, Z-4 and Z-5, with decreasing purple color and increasing green color. These plants were self-bred to the seventh generation, and then used for analysis. The plants were pot-planted from April to May at seedling stage. Each pot contained $5000 \mathrm{~g}$ soil with $100 \mathrm{mg} \mathrm{kg}^{-1}$ rapidly available nitrogen, $3.5 \mathrm{mg} \mathrm{kg}^{-1}$ rapidly available phosphorus, $180 \mathrm{mg} \mathrm{kg}^{-1}$ rapidly available potassium, $1.1 \mathrm{~g} \mathrm{~kg}^{-1}$ organic matters. All pots were maintained in the Hunan Agricultural University germplasm nursery with regular water and fertilizer management. At the stage of 6 true leaves, the plants were selected with the same growth trend and then were pre-cultured in the light incubator for 2 days. Temperature was at $28{ }^{\circ} \mathrm{C}$, and the relative humidity was about $60 \%$. The light was $16 \mathrm{~h}$ in the daytime, $8 \mathrm{~h}$ in the night, and the illumination was $7000 \mathrm{~lx}$. Three repetitions for treatment and 20 plants per repetition were performed and the plants were observed for two consecutive years. Some plants were randomly selected as samples after treatment.

\subsection{Pigment Analysis}

Acetone of $95 \%$ was used to extract leaf samples, and the pigment was measured by spectrophotometry (Ruili UV-2100, Beijing, China) at 663, 645, and $470 \mathrm{~nm}$ wavelengths. Chlorophyll (Chl) a, Chl b, carotenoids, and carotene (Car) were then calculated based on the study from Arnon et al. [8].

\subsection{Total Anthocyanin Analysis}

The method by Lin et al. and Pirie et al. $[9,10]$ was used to measure the anthocyanin content. Briefly, $0.2 \mathrm{~g}$ fresh leaf tissue was collected, and the anthocyanins were extracted with acidified methanol $\left(10 \mathrm{~mL}, 99 \mathrm{CH}_{3} \mathrm{OH}: 1 \mathrm{HCl}, v / v\right)$ at $4{ }^{\circ} \mathrm{C}$ for $24 \mathrm{~h}$ in dark. The extraction was then centrifuged at $12,000 \times g$ for $2 \mathrm{~min}$, and the absorbances of supernatants were measured at optical density (OD) 530 and $600 \mathrm{~nm}$ with a UV-visible spectrophotometer (UV-2550, Shimadzu, Japan). The unit of anthocyanin concentration was $\mathrm{U}^{-g^{-1}}{ }^{-1}$, where $\mathrm{U}$ was calculated from $\left(\mathrm{OD}_{530}-\mathrm{OD}_{600}\right) / 0.1$.

\subsection{Gas Exchange Analysis}

The LI-6400 portable photosynthesis system (manufactured by LI-COR, Lincoln, NE, USA) was used to measure photosynthetic rate. The instantaneous photosynthetic rate under a light intensity of $1000 \mu \mathrm{mol}$ photons $\cdot \mathrm{m}^{-2} \cdot \mathrm{s}^{-1}$, the stomatal conductance $\left(\mathrm{g}_{\mathrm{s}}\right)$, the transpiration rate $(E)$, and other gas exchange parameters of leaves were measured on the last full-length leaf at 9:00 to 11:00 am. The air temperature was $32 \pm 0.5^{\circ} \mathrm{C}$ at the time of measurement, and each plant had 3-5 leaves being measured.

The tests were performed during the flowering period of plants. When there were more than 3 consecutive sunny days, we conducted the measurements from 9:00 to 11:30 am using a portable photosynthetic system (Li-6400, Lincoln, NE, USA) with 6400-02B red and blue light source. The healthy leaves with no disease spots were selected, and the impurities on leaf surface were gently swiped off with brush before measurement. Three plants were measured in each purple type, and 3-4 leaves were measure on each plant. The measurement was repeated consecutively for 3 days, and the mean value was calculated. The photosynthetically active radiation (PAR) was set to $0,60,100,150,200,250,500,750$, $1000,1200,1500$, and $2000 \mu \mathrm{mol} \cdot \mathrm{m}^{-2} \cdot \mathrm{s}^{-1}$, respectively. The net photosynthetic rate $(\mathrm{Pn})$, stomatal conductance (Cs), intercellular $\mathrm{CO}_{2}$ concentration $(\mathrm{Ci})$, and transpiration rate (Tr) were directly measured by the photosynthetic system. During the measurements, leaf temperature was $(32.13 \pm 0.24){ }^{\circ} \mathrm{C}$, gas flow rate was $(500 \pm 0.01) \mu \mathrm{mol} \cdot \mathrm{s}^{-1}, \mathrm{CO}_{2}$ 
concentration in sample room was $(350.69 \pm 1.74) \mu \mathrm{mol} \cdot \mathrm{mol}^{-1}$, and the relative humidity was $47.95 \% \pm 0.95 \%$.

\subsection{High Temperature Treatment}

The plant grown under $28^{\circ} \mathrm{C}$ before treatment was used as the control. At the stage of 6 true leaves, all the plants were placed in an illumination incubator for high temperature treatment at $40{ }^{\circ} \mathrm{C}$ for $16 \mathrm{~h}$ during the day and $8 \mathrm{~h}$ at night. The relative humidity is about $60 \%$ and the illumination is $7000 \mathrm{~lx}$. The treatment lasted for $48 \mathrm{~h}$, during which the water was normally replenished to prevent drought stress. Samples were taken both before and after treatment.

\subsection{Proline Determination}

The freshly collected leaves were washed and the dried with clean tissue paper. The rim and vein were removed, and the remaining leaves were cut into pieces (about $0.5 \mathrm{~g}$ ). Then, leaf samples were mixed with $5 \mathrm{~mL}$ of $3 \%$ sulfosalicylic acid solution in a large tube, which was boiled for $10 \mathrm{~min}$ with shaking. After cooling down, the extract was filtered into a clean tube, and then mixed with acetic acid and ninhydrin at a ratio of 1:1:1, $2 \mathrm{~mL}$ for each. This mixture was then sealed with plastic wrap and boiled for $30 \mathrm{~min}$. A total of $4 \mathrm{~mL}$ toluene was added into the mixture after it was cooled down, and the upper red solution was collected to measure its absorption at $520 \mathrm{~nm}$, with toluene as the reference. Based on the standard curve, we can calculate the proline concentration $\times\left(\mu \mathrm{g} \cdot \mathrm{mL}^{-1}\right)$ in the sample; and $\mathrm{x}$ can be used to calculate the proline concentration in fresh leaves with the formula: Proline content $\left(\mu \mathrm{g} \cdot \mathrm{g}^{-1}\right)=(\mathrm{x} \times 5 / 2) /$ fresh leaf weight $(\mathrm{g})$.

\subsection{Soluble Sugars}

Soluble sugars were measured by anthrone colorimetry. A total of $0.1 \mathrm{~g}$ of fresh leaves were put into a ground glass weighing bottle, and $20 \mathrm{~mL}$ of distilled water was added. The sample was extracted in boiling water twice, each time lasted for $30 \mathrm{~min}$; the extract was then filtered into a $50 \mathrm{~mL}$ volumetric flask. The weighing bottle and residues were washed and filtered for a few more times, and the water was also collected into the volumetric flask. After that, the volumetric flask was filled to the constant volume with water and well mixed. Then, $0.5 \mathrm{~mL}$ sample extract was taken, and mixed thoroughly with distilled water $(1.5 \mathrm{~mL})$, anthrone ethyl acetate solution $(0.5 \mathrm{~mL})$ and concentrated sulfuric acid $(5 \mathrm{~mL})$. The mixture was immediately heated in boiling water bath for $1 \mathrm{~min}$. After, the sample was cooled down to room temperature and its absorbance was measured at $630 \mathrm{~nm}$. The final soluble sugar content was calculated from the standard curve: soluble sugar $\left(\mu \mathrm{g} \cdot \mathrm{g}^{-1} \mathrm{FW}\right)=[$ corresponding sucrose content from standard curve $(\mu \mathrm{g}) \times$ total extract volume $(\mathrm{mL}) /$ measurement volume $(\mathrm{mL}) /$ sample fresh weight $(\mathrm{g})$.

\subsection{Antioxidant Enzyme Activity}

The following measurements were performed with commercial kits (Nanjing Jiancheng Bioengineering Institute, Nanjing China. http:/ / www.njjcbio.com/ (accessed date: 10 September 2020)): colorimetric method was used to measure hydroxyl free radical $(\cdot \mathrm{OH})$, peroxidase (POD), and glutathione reductase (GR); thiobarbituric acid method was used to measure malondialdehyde (MDA); hydroxylamine method was used to measure superoxide dismutase (SOD); and ammonium molybdate method was used to measure catalase (CAT).

\subsection{Statistical Analysis}

In this study, the results were expressed as "mean \pm standard error", and the data were analyzed by one-way analysis of variance (ANOVA) with Excel 2003 and SPSS 17.0. LSD method was used for pairwise comparison and significance analysis $(p<0.05)$. 


\section{Results}

\subsection{Comparison of Leaf Pigment Content}

There were some differences in the relative contents of anthocyanin, $\mathrm{Chl} b$, and Carotenoids in the leaves of different purple peppers, but there was no significant difference in the content of chlorophyll a. Among all the purple types, Z3 had the highest $\mathrm{Chl} b$ and Carotenoid contents, and the parental PF(CS3) and Z1 had the highest anthocyanin content. On the contrary, the parental GM(SJ11-3) and Z5 had the lowest anthocyanin content (Table 1).

Table 1. Pigment content of different purple peppers.

\begin{tabular}{ccccc}
\hline & Chl a & Chl b & Carotenoid & Anthocyanin \\
\hline & & mg g $^{-\mathbf{1}} \mathbf{~ D W}$ & & $\mathbf{U} \cdot \mathbf{g}^{-\mathbf{1}}$ \\
\hline PF(SJ11-3) & $9.73 \pm 0.58$ & $4.73 \pm 6.32 \mathrm{~b}$ & $1.61 \pm 6.22 \mathrm{a}$ & $53.09 \pm 3.65 \mathrm{a}$ \\
Z1 & $9.63 \pm 0.26$ & $4.81 \pm 8.61 \mathrm{~b}$ & $1.60 \pm 5.64 \mathrm{a}$ & $54.08 \pm 5.24 \mathrm{a}$ \\
Z2 & $9.77 \pm 0.65$ & $5.48 \pm 6.76 \mathrm{a}$ & $1.68 \pm 3.35 \mathrm{a}$ & $47.12 \pm 3.69 \mathrm{~b}$ \\
Z3 & $9.81 \pm 0.62$ & $5.51 \pm 10.25 \mathrm{a}$ & $1.69 \pm 8.62 \mathrm{a}$ & $40.25 \pm 2.26 \mathrm{c}$ \\
Z4 & $9.59 \pm 0.64$ & $4.03 \pm 3.65 \mathrm{c}$ & $1.53 \pm 5.62 \mathrm{~b}$ & $34.18 \pm 3.04 \mathrm{~d}$ \\
Z5 & $9.42 \pm 0.88$ & $3.59 \pm 6.75 \mathrm{~d}$ & $1.45 \pm 8.95 \mathrm{~b}$ & $24.29 \pm 1.98 \mathrm{e}$ \\
GM(CS3) & $9.53 \pm 0.56$ & $3.54 \pm 8.80 \mathrm{~d}$ & $1.54 \pm 6.21 \mathrm{~b}$ & $23.57 \pm 3.68 \mathrm{e}$ \\
\hline
\end{tabular}

Note: PF-purple female; GM—green male. Lowercase means significance at 0.05 levels. Means of 10 replications \pm SE.

\subsection{Comparison of Photosynthesis Characteristics}

Except for Z1, there was no significant difference in net photosynthetic rate between different purple peppers; when compared to the parents, the photosynthetic rates of different purple progenies were similar to that of the green pepper parents but were significantly higher than that of the purple parents. Under high temperature conditions, all plants showed decreased photosynthesis rates. Z1, Z2, Z3, and PF were decreased $54.6 \%, 54.3 \%, 51.4 \%$, and $52.9 \%$, respectively; they showed significantly smaller reduction compared to Z4, Z5, and GM $(62.6 \%, 69.6 \%$ and $73.9 \%$, respectively) (Table 2$)$.

Table 2. $P_{\mathrm{N}}, E$, and $\mathrm{g}_{\mathrm{s}}$ of different peppers.

\begin{tabular}{|c|c|c|c|c|c|c|c|c|c|}
\hline & \multicolumn{3}{|c|}{$P_{\mathrm{N}} / \mu \mathrm{mol} \mathrm{CO} \mathrm{CO}^{-2} \cdot \mathrm{s}^{-1}$} & \multicolumn{3}{|c|}{$E / \mathrm{mmol} \cdot \mathrm{m}^{-2} \cdot \mathrm{s}^{-1}$} & \multicolumn{3}{|c|}{$\mathrm{g}_{\mathrm{s}} / \mathrm{mol}\left(\mathrm{H}_{2} \mathrm{O}\right) \cdot \mathrm{m}^{-2} \cdot \mathrm{s}^{-1}$} \\
\hline & $28^{\circ} \mathrm{C}$ & $40^{\circ} \mathrm{C}$ & $-\%$ & $28^{\circ} \mathrm{C}$ & $40^{\circ} \mathrm{C}$ & $-\%$ & $28^{\circ} \mathrm{C}$ & $40^{\circ} \mathrm{C}$ & $-\%$ \\
\hline PF & $14.34 \pm 1.25 b$ & $6.75 \pm 0.12$ & $52.9 \mathrm{c}$ & $3.79 \pm 0.58 c$ & $0.85 \pm 0.05$ & $77.6 \mathrm{c}$ & $0.49 \pm 0.05 c$ & $0.24 \pm 0.02$ & $51.0 \mathrm{c}$ \\
\hline Z1 & $14.25 \pm 1.31 b$ & $6.47 \pm 0.54$ & $54.6 \mathrm{c}$ & $4.59 \pm 0.89 \mathrm{a}$ & $0.82 \pm 0.06$ & $82.1 \mathrm{~b}$ & $0.48 \pm 0.03 c$ & $0.25 \pm 0.03$ & $47.9 \mathrm{~d}$ \\
\hline Z2 & $17.64 \pm 1.28 \mathrm{a}$ & $8.07 \pm 0.82$ & $54.3 \mathrm{c}$ & $3.95 \pm 0.57 b$ & $0.75 \pm 0.08$ & $81.0 \mathrm{c}$ & $0.60 \pm 0.07 \mathrm{a}$ & $0.29 \pm 0.04$ & $51.7 \mathrm{c}$ \\
\hline Z3 & $17.88 \pm 1.64 \mathrm{a}$ & $8.69 \pm 0.68$ & $51.4 \mathrm{c}$ & $4.15 \pm 1.04 b$ & $0.89 \pm 0.11$ & $78.6 \mathrm{c}$ & $0.61 \pm 0.05 \mathrm{a}$ & $0.32 \pm 0.02$ & $47.5 \mathrm{~d}$ \\
\hline $\mathrm{Z4}$ & $16.15 \pm 1.08 \mathrm{a}$ & $6.04 \pm 0.69$ & $62.6 \mathrm{~b}$ & $3.63 \pm 0.87 \mathrm{~d}$ & $0.63 \pm 0.08$ & $82.6 \mathrm{~b}$ & $0.54 \pm 0.04 \mathrm{~b}$ & $0.21 \pm 0.03$ & $61.1 \mathrm{~b}$ \\
\hline $\mathrm{Z5}$ & $17.61 \pm 1.20 \mathrm{a}$ & $5.35 \pm 0.64$ & $69.6 \mathrm{a}$ & $3.64 \pm 0.74 \mathrm{~d}$ & $0.51 \pm 0.07$ & $86.0 \mathrm{a}$ & $0.53 \pm 0.05 b$ & $0.19 \pm 0.02$ & $64.2 \mathrm{a}$ \\
\hline GM & $16.21 \pm 1.07 \mathrm{a}$ & $4.23 \pm 0.45$ & $73.9 a$ & $3.61 \pm 0.65 \mathrm{~d}$ & $0.52 \pm 0.06$ & $85.6 \mathrm{a}$ & $0.57 \pm 0.03 \mathrm{~b}$ & $0.19 \pm 0.03$ & $66.7 \mathrm{a}$ \\
\hline
\end{tabular}

Note: PF-purple female; GM—green male. Lowercase means significance at 0.05 levels. Means of 10 replications $\pm \mathrm{SE}$.

The transpiration rate was the highest in Z1, followed by Z3 and Z2; Z4 and Z5 were not different from the green parents. Under high temperature conditions, all plants showed decreased transpiration rate, and Z5 and GM had the highest reduction, while Z3 and PF had the smallest reduction (Table 2).

The stomatal conductance was higher in Z2 and Z3 than that in others. Under high temperature conditions, all plants showed decreased stomatal conductance, $\mathrm{Z} 3$ had the smallest reduction and GM had the highest reduction (Table 2).

\subsection{Comparison of Light Response Curves}

Within a certain range of light intensity, the photosynthetic rates of all seven plants increased with the increase of light intensity, but their performance under strong light was different. PF, Z1, Z2, and Z3 had no light saturation point at the intensity of $2000 \mu \mathrm{mol}$ photons $\cdot \mathrm{m}^{-2} \cdot \mathrm{s}^{-1}$, and the photosynthetic rate of $Z 3$ was significantly higher than that of others, 
reaching the maximum $\left(20.16 \mu \mathrm{mol} \cdot \mathrm{m}^{-2} \cdot \mathrm{s}^{-1}\right)$ under the intensity of $2000 \mu \mathrm{mol} \cdot$ photons $\cdot \mathrm{m}^{-2} \cdot \mathrm{s}^{-1}$; $\mathrm{Z4}, \mathrm{Z5}$, and GM exhibited photoinhibition under strong light, and their maximum photosynthetic rate was lower than that of Z1, Z2, and Z3 (Figure 1).

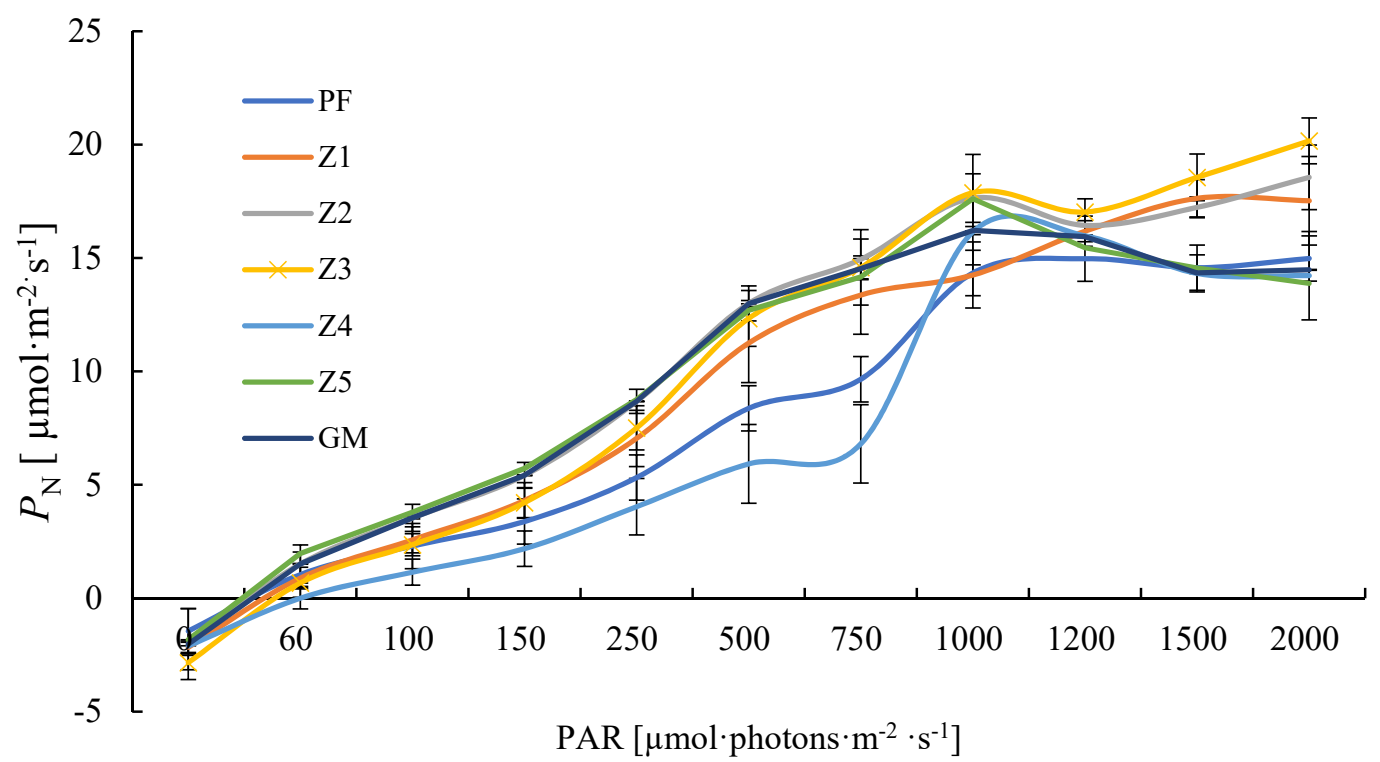

Figure 1. Light response curve of $P_{\mathrm{N}}$ of different materials. Note: PF-purple female; GM-green male. Means of 10 replications $\pm \mathrm{SE}$.

\subsection{Enzyme Activity}

After high temperature treatment at $40{ }^{\circ} \mathrm{C}$, the enzyme activities of different antioxidant systems responded differently: SOD and GR showed decreased activities, whereas CAT and POD (except GM) showed increased activities. Moreover, the reduction and increase in enzyme activity were different in different plants: PF, Z1, Z2, and Z3, which showed deeper purple color, less reduced SOD and GR activities, and more increased CAT and POD activities; in addition, these four enzymes of $\mathrm{Z} 3$ were all at high levels under high temperature conditions (Figure 2).

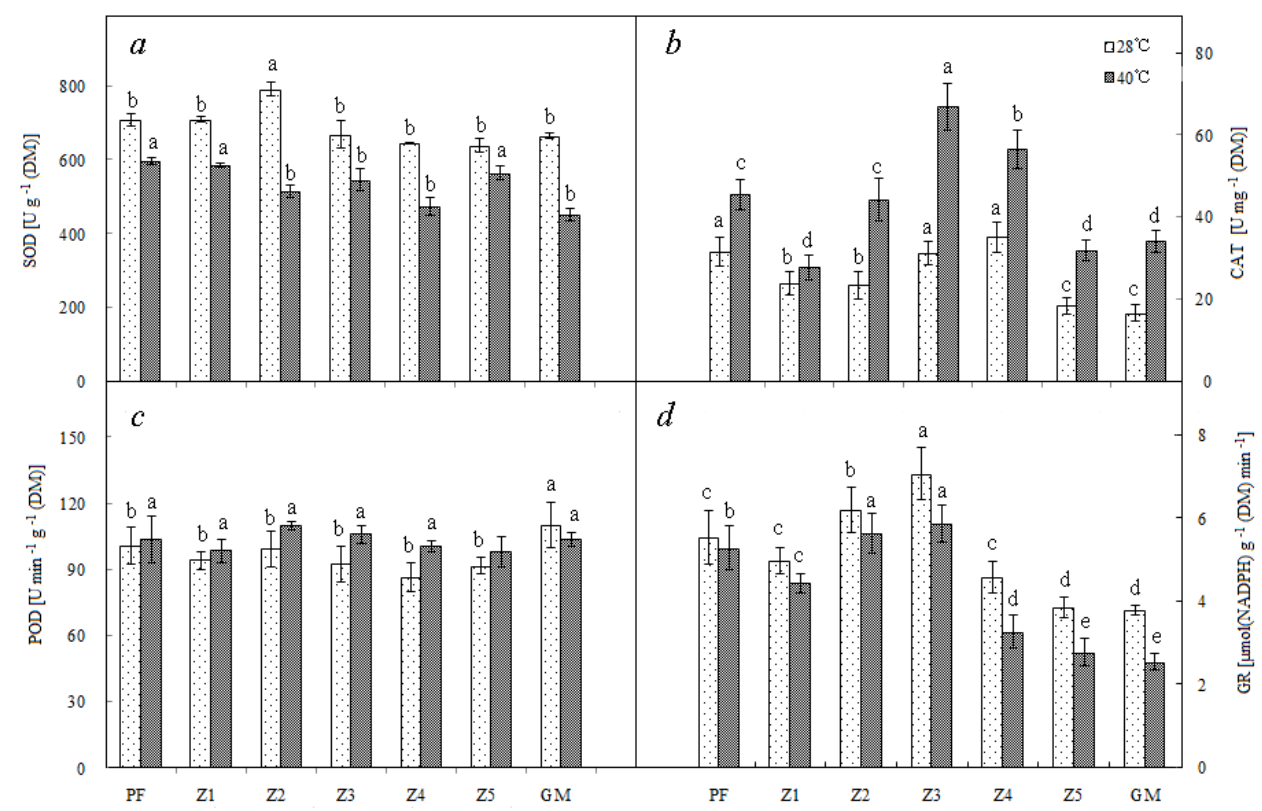

Figure 2. Superoxide dismutase (SOD) (a), catalase (CAT) (b), peroxidase (POD) (c), and Glutathione reductase (GR) (d) of different materials. Note: PF-purple female; GM-green male. Lowercase means significance at 0.05 levels. Means of 10 replications \pm SE. 


\subsection{Content Comparison}

Under normal temperature conditions, the plants with darker purple color had higher content of soluble sugar: PF, Z1, and Z2 had significantly more soluble sugar than others. Under high temperature conditions, the contents of soluble sugar and proline in leaves were increased in all plants, and PF, Z1, Z2, and Z3 showed more increase than others (Figure 3a,b).

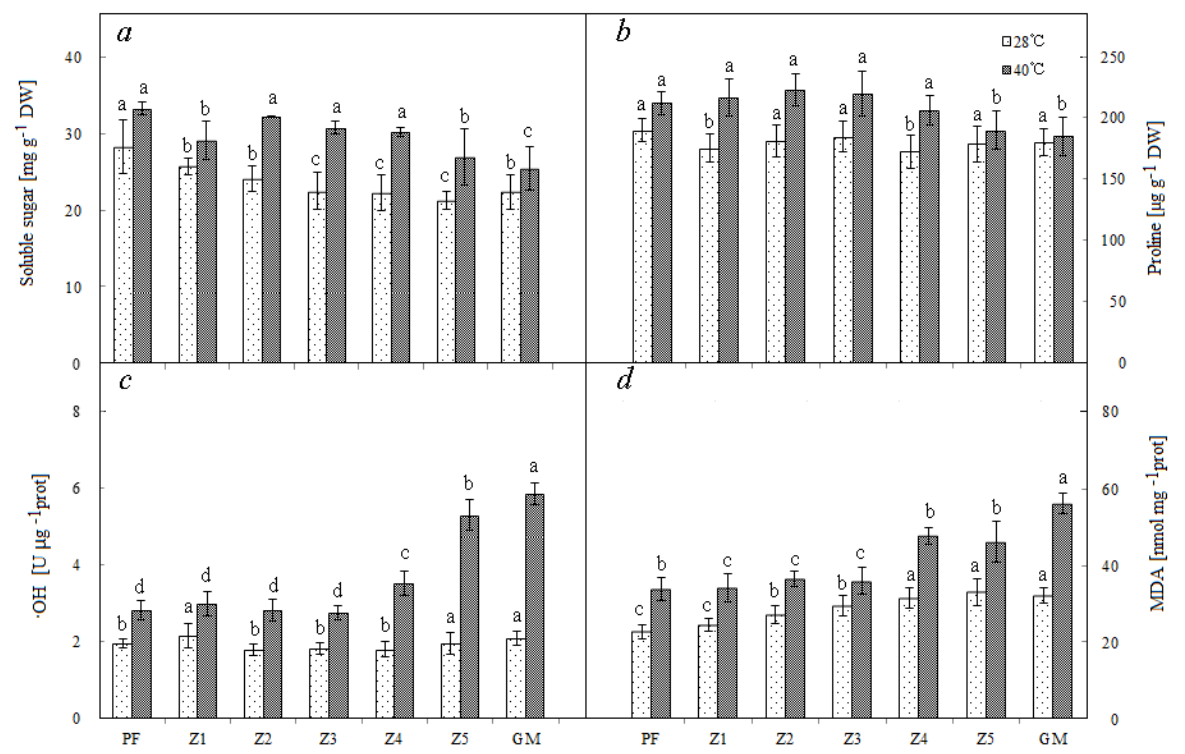

Figure 3. Soluble sugar (a), proline (b), $\cdot \mathrm{OH}(\mathbf{c})$, and MDA (d) of different materials. Note: PF-purple female; GM—green male. Lowercase means significance at 0.05 levels. Means of 10 replications $\pm \mathrm{SE}$.

\subsection{Comparison of Oxidation Product}

Under normal temperature conditions, the $\mathrm{OH}$ contents were similar among all seven plants. When temperature was high, the $\mathrm{OH}$ contents were increased in all plants, but $\mathrm{PF}$, Z1, Z2, and Z3, which had darker purple color, showed significantly less increase than other plants (Figure 3c). PF and Z1, the two with deepest purple color, had significantly lower MDA content than other plants under normal temperature. When temperature was high, the MDA contents of all plants increased, but PF, Z1, Z2, and Z3 showed significantly less increase than the other three (Figure 3d).

\section{Discussion}

Anthocyanins can protect plants from photo-damaging effects. It absorbs the excess light energy and prevents the light damage on photosynthetic structures, resulting in reduced photoinhibition from strong light. For example, the anthocyanins in eggplant leaves can capture the high-energy blue-green light, so that it effectively protects the PSI and PSII reaction centers and maintains the functional coordination of the reaction centers [11]. Moreover, anthocyanins can effectively eliminate the active oxygen damage caused by environmental stresses. For example, the red amaranth and purple leaf rice, which have high anthocyanin levels, are more resistant to photooxidation damage [12]. In our study, we found that the plants with more anthocyanin (darker purple) showed no light saturation point within a certain light range, and had higher antioxidant enzyme activities, lower $\cdot \mathrm{OH}$, and higher MDA contents under high temperature, indicating that the peppers with darker purple color exhibit better resistance to strong light and high temperature stresses.

Anthocyanins can affect the photosynthetic capacity of plants. Studies have shown that the net photosynthetic rates of anthocyanin-containing plants, such as red leaf peach [13], purple leaf peach [14], purple leaf plum [15], purple cabbage [16,17], purple perilla [18], coleus blumei [19,20], red Loropetalum chinense [21], red leaf rose apple [22] and purple 
leaf Cotinus coggygria [23], were lower than the corresponding green plants. Our study found that among the progenies that had much lower anthocyanin than the purple parents, there was no significant difference in net photosynthetic rate; moreover, the photosynthetic rates of these progenies were similar to the green parents, but significantly higher than the purple parents. In addition, the photosynthetic rate of Z1 plant, which had similar anthocyanin content as the purple parents, was similar to the purple parents, but significantly lower than other plants that had lower anthocyanin content. These results indicate that high anthocyanin level can affect the photosynthetic rate, but moderate anthocyanin content has little effect on photosynthesis.

In summary, the pepper with purple leaves, which contains more anthocyanin, has higher resistance to strong light and high temperature. But the high anthocyanin content also affects the photosynthetic rate. Therefore, we recommend selecting the plants with obvious purple color in the hybrid progenies from purple leaf pepper with high anthocyanin content and green leaf pepper with little anthocyanins. The selected plants should have moderate anthocyanin content and high photosynthetic rate, which results in high yield and good resistance to environmental stresses such as strong light and high temperature.

Author Contributions: Conceptualization, L.O. and Y.H.; methodology, X.W.; software, H.S.; validation, C.F., M.C. and X.Z.; formal analysis, Y.H.; investigation, M.C. and W.M.; resources, L.O.; data curation, H.S.; writing-original draft preparation, Y.H.; writing-review and editing, L.O.; project administration, L.O.; funding acquisition, L.O. All authors have read and agreed to the published version of the manuscript.

Funding: This research was funded by the Key Research and Development Program of Hunan (2019NK2191) and the China Agriculture Research System (CARS-24-A-05).

Institutional Review Board Statement: Not applicable.

Informed Consent Statement: Not applicable.

Conflicts of Interest: The authors declare no conflict of interest.

\section{Abbreviations}

Chl-chlorophyll; DW-dry weight; E-transpiration rate; GM-green male; gs-stomatal conductance; GR-glutathione reductase; MDA-malondialdehyde; $\cdot \mathrm{OH}$-hydroxyl free radical; PF-purple female; PN-net photosynthetic rate; SOD-superoxide dismutase; POD-peroxidase.

\section{References}

1. Teng, Y.D.; Xu, X.S.; Chen, X.Q. Pepper germplasm resources of Southwest Sichuan. China Veg. 1997, 17, 29-32.

2. Sui, Y.H.; Zhang, Z.X.; Xing, S.Z.; Ling, T.Z.; Jin, G.F. Research on some physiologic indexes and germination of purple chili line YN99007 under NaCl stress. J. Anhui Tech. Teach. Coll. 2004, 21, 27-29.

3. Sui, Y.H.; Zhang, Z.X.; Xing, S.Z.; Lu, X.M.; Guo, Z.M. Effect of temperature on some physiologic indexes and germination of purple chili line YN99007. Seed 2005, 24, 19-20.

4. Sui, Y.H.; Qian, C.T.; Chen, J.F.; Shi, J.L.; Hu, N.B.; Cao, Y.J. Fruit setting rate and major photosynthetic characteristics of purple chili peppers during summer conditions. Acta Hortic. Sin. 2011, 38, 77-86.

5. Zhang, Q.A.; Fang, L.; Dong, Y.X.; Jiang, H.K.; Yan, C.S.; Wang, Y.Q.; Fang, Q.L. ZiYan 1 hao, a new purple peper variety. J. Chang. Veg. 2005, 22, 6 .

6. Jiang, H.K.; Wang, P.C.; Wang, Y.; Jia, L.; Tian, H.M.; Yan, C.S.; Fang, L.; Zhang, Q.A. Breeding of purple pepper variety “Zijin 1 hao" of facility cultivation. Auhui Agric. Sci. Bull. 2017, 23, 50-51.

7. Li, Z.; Liu, J.B.; Diao, W.P.; Wang, S.B.; Pan, B.G.; Ge, W.; Guo, G.J. Research and analysis of the expression of anthocyanin biosynthesis related gene in pepper. Acta Agric. Boreali-Sin. 2014, 29, 87-92.

8. Arnon, D.I. Copper enzymes inisolated chloroplasts phenoloxidases in Beta vulgaris. Plant Physiol. 1949, 24, 1-15. [CrossRef]

9. Lin, Z.F.; Li, S.S.; Chang, D.L.; Lin, G.Z.; Li, Y.B.; Liu, S.X.; Chen, M.D. The changes of pigments, phenolics contents and activities of polyphenol oxidase and phenylalanine ammonialyse in pericarp of postharvest litchi fruit. J. Integr. Plant Biol. 1988, 30, 40-45.

10. Pirie, A.; Mullins, M.G. Changes in anthocyanin and phenolics content of grapevine leaf and fruit tissues treated with sucrose, nitrate, and abscisic acid. Plant Physiol. 1976, 58, 468-472. [CrossRef] [PubMed]

11. Xue, Z.J.; Gao, Z.K.; Wang, M.; Zhong, C.F.; Gao, R.F. Protective action on photosynthetic apparatus by purple anthocyanin in the epidermal cells of eggplant (Solanum melongena L.) leaves. Acta Ecol. Sin. 2009, 29, 1374-1381. 
12. Peng, C.L.; Lin, Z.F.; Lin, G.Z.; Chen, S.W. The anti-photooxidation of anthocyanins-rich leaves of a purple rice cultivar. Sci. China Ser. C Life Sci. 2006, 36, 209-216. [CrossRef]

13. Jaing, W.B.; Zhuang, M.; Shen, Z.J.; Song, H.F.; Cao, J.; Li, G. Study on the photosynthetic characteristics of red-leaf peach and purple-leaf plum in different seasons. Acta Hortic. Sin. 2006, 33, 577-582.

14. Liu, H.; Li, B.Y.; Ma, J.; Zhou, X.M. Study on photosynthetic characteristics and influencing factors of purple peach and green leaf peach. J. Anhui Agric. Sci. 2004, 32, 318-320.

15. Zhang, M.; Jiang, W.B.; Song, H.F.; Ma, R.J. Comparison of photosynthetic characteristics between purple-leaf plum and red beauty plum (green leaf). Jiangsu J. Agric. Sci. 2006, 22, 154-158.

16. Tang, R.; Huang, Z.S.; Wang, H.; Dai, W.D.; Wang, S.M.; Li, D.Z. Pigment changes and photosynthetic physiological characteristics in rapeseed with purple-red leaf. Southwest China J. Agric. Sci. 2016, 29, 1270-1275.

17. Wang, M.L.; Ai, X.Z.; Ding, F.; Wang, H.T.; Liang, W.J. Comparation of the photosynthetic characteristics of purple cabbage and cabbage. Acta Hortic. Sin. 2008, 35, 547-553.

18. Sui, L.; Wang, K.C.; Liang, Y.F.; Xue, Q. The relationships between leaf anatomical structure, anthocyanins and photosynthetic characteristics in Perilla frutescens. Chin. J. Ecol. 2017, 36, 1590-1596.

19. Weisburg, L.A.; Wimmers, L.E.; Turgeon, R. Photoassimilate transport characteristics of nonchlorophyllous and green tissue invariegated leaves of Coleus blumei Benth. Planta 1988, 175, 1-8. [CrossRef] [PubMed]

20. Burger, J.; Edwards, G.E. Photosynthetic efficiency and photodamage by UV and visible radiation in red versus green leaf coleus varieties. Plant Cell Physiol. 1996, 37, 395-399. [CrossRef]

21. Tang, Q.R. Study on the chloroplast ultrastructure of loropetalum chinensis var.rubrumyien and L.Chinensis. J. Hunan Agric. Univ. 2003, 29, 41-42.

22. Dodd, I.C.; Critchley, C.; Woodall, G.S.; Stewart, G.R. Photoinhibition in differently colored juvenile leaves of Syzygium species. J. Exp. Bot. 1998, 49, 1437-1445. [CrossRef]

23. Chen, L.; Pan, Q.H.; Jin, H. Research on influence of relative humidity and air temparature on photosynthetic characteristics of cotinus coggygria 'purpureus'. Chin. Agric. Sci. Bull. 2008, 24, 124-128. 